\title{
The Management on the Multimedia Classroom Based on the Internet of Things
}

\author{
Lei GAN \\ Tangshan college, HeBei, China
}

\begin{abstract}
According to the present problems of multimedia classroom in use, maintenance, management, A control system Based on the Internet of things is propsed. Through the system, it can alarm to remote control, equipment condition monitoring, data analysis and processing. This paper expounds the structure of the system, and gives the specific working mode.
\end{abstract}

KEYWORD: management; multimedia classroom; the Internet of things

\section{INTRODUCTION}

With the continuous development of information technology, information technology education has been fully set out in our country. Multimedia network teaching has become an indispensable tool. These objective conditions for the construction of multimedia classrooms, equipment maintenance and management puts forward new requirements. Due to the different time of the construction of the multimedia classroom, the teaching, have different specifications of the equipment. For daily maintenance in management it caused too much difficulty. In the actual maintenance, it is largely through the artificial. if different classroom problems happened in the same time, it requires long time to repair. Obviously the work efficiency is low. what is more, it delayed the normal teaching. It is very important to How to use digital campus Internet of things to solve this problem, the maximum improve work efficiency, improve the work style to promote the management level of the multimedia classroom.

\section{THE SYSTEM ANALYSIS AND DESIGN}

The multimedia classroom is basically by the central computer, projector, projection screen, DVD, speaker, microphone, etc. Teachers in the process of using are usually open the central and local to open one button. Other control button basically do not have to use. so the control utilization rate is very low. Through campus network transmission, the various components of the sensor can transmit in remote control, if the remote management problems at the same time, you can switch to local mode, manual switch. So it can increase the frequency of the correct use of multimedia equipment, reduce the influence due to improper operation time in the class. Equipment management in the classroom, the teacher usually phone the computer administrator, and then the administrato go to the class quickiy, the general problems in class most of the time, it takes time to solve the problem, such consumption greatly reduce the efficiency as well as the class time, affected the class. We can Design the classroom inside different devices through sensor acquisition and calculation, according to different classroom equipment, the equipment maintenance of the critical value can be set through the system. For example, General projector screen pack, usually work well in 100 hours, if it is used in more than 100 hours, the projector can't start. We can be as the device USES actual data collection, summary, analysis, by comparing with set ahead of the critical value, close to the critical value of warning, timely maintenance. Such practice makes multimedia maintenance work become passive to active, improve work efficiency. In the multimedia classroom management, which is the current classroom is bad, will replace the classroom, the data is not comprehensive, could not cross the use of actual consumption statistics, it can design fault condition can be collected, stated, and can according to the semester, according to the classroom, according to equipment for different horizontal comparative analysis, provide the data basis for the specific management.

Based on the above, this paper proposes a multimedia classroom management system based on Internet of things technology, through the digital 
campus network interfaces, sensor data acquisition technology, various multimedia classroom in the early period of the equipment maintenance, use of control testing, data collection in a body after use, improve the multimedia classroom utilization to a great extent. Main function is: the first USES the local IC card and the central control panel to operate. IC card face include the identity information of the teacher and class time, can use in this time, the rest of the time is not authorized to open equipment. On network control, and contains the classroom equipment of the remote control switch, authorization, batch reset switch, automatic switch and office schedule real-time matching function. At the same time, the remote management due to reasons such as the network cannot be used, can be used through local switch of the classroom. So to avoid the excessive use of the equipment, reduce the damage to equipment due to improper boot way, increase the service life of equipment, improve the working efficiency. Secondly, using the content diagnosis technology such as sensor, to different classrooms of different types of specialized testing equipment. The projector screen pack use time and use the time to read light bulbs, can quickly of the current status of using makes the work can be solve the problem before. At the same time can also be inspection on the equipment such as computer, read some hardware information, including hard disk usage information, the temperature of the CPU usage, and other equipment, etc. Can remote assistance at the same time teachers as teaching software and the installation of the virus, unloading, updates, upgrades, backups, etc. To enhance the work initiative. Finally, through the daily usage of the equipment as well as the relevant situation of failure, through the sensor, the remote management will appear all sorts of comparative analysis. Through the analysis of these data can be equipment replacement, provides the reference for the purchase of equipment accessories. To improve the authenticity and reliability of the data. Provide a scientific basis for the decision-making for leadership. System diagram as shown in figure 1, multimedia classroom equipment connection diagram is shown in figure 2 .

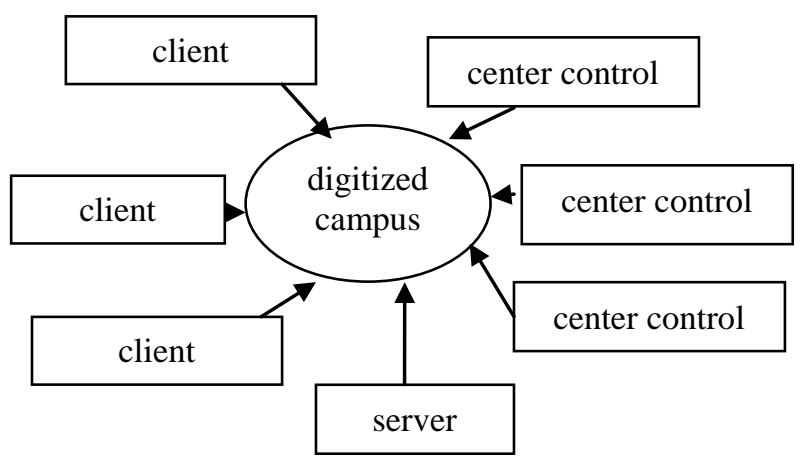

Figure 1 System topology

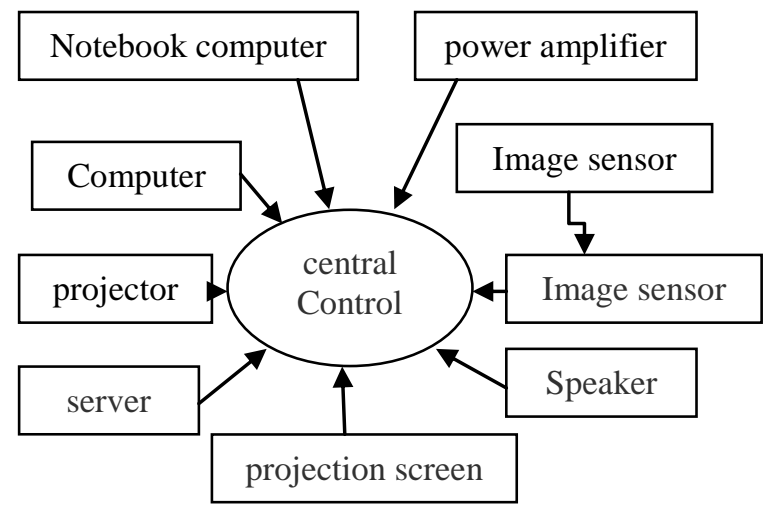

Figure 2 The network multimedia classroom equipment connection diagra

\section{ALL PARTS OF SYSTEM IMPLEMENTATION}

Network multimedia classroom management system USES embedded ARM processor, besides can realize the calculation of the local data operation can also through the campus network, and web server, remote control for multimedia classroom equipment. At the same time use the sensors such as current, voltage, audio and image technology, judgment analysis was carried out on the collection of information, make a judgment

\subsection{Output power control}

Classroom control system has a 5-8 road power output interface. Can make all the external power supply equipment. When press "class" of central, central will, in turn, in order to various external power supply equipment, the instantaneous voltage cause the least damage to the equipment, in the same way, in case of power failure or class power automatic control in sequence, and the design time delay switch.

\subsection{The control of the desktops, projectors and control electric curtain}

Control of the desktop and projection is composed of sensors, collection and processing by the server Settings to each room type control code entry on the sensor. Can read the desktop computer hard disk, $\mathrm{CPU}$, and the use time of projector, screen pack service life, etc. Now class, all of these data detection is completed through the campus network to the server, convenient for management personnel to use of the classroom equipment. To detect electric curtain, control of open, the motor current detection function will be to click detection is working correctly, and image sensor can judge according to the movement of the curtain fell will rise. If the curtain is abnormal, the control will be forced to cut off the curtain power, protect the curtain motor, at 
the same time the abnormal signal transmission to the server.

\subsection{Manual and automatic switching}

When occurrence problem of campus network to remote control, can undertake independent standalone mode, the control can convert to manual mode, you can through the corresponding button panel of each equipment operation, ensure the multimedia teaching smoothly.

\section{THE SUMMARY AND OUTLOOK}

Internet of things is the hotspot in the forefront of international attention on the research field, has caused the attention from the academia and industry, is considered to have a great influence in the $21 \mathrm{st}$ century [1]. And the system is based on multimedia classroom management for many years, constantly summarize and explore, in view of the problems in practice are analyzed and judgment on the basis of the development. Can not only in the early stage of the equipment of the early warning, and in the middle of the problems existing in the use of the late for rapid response to solve and the actual management of scientific data analysis. To a certain extent, simplifies the operation steps, reduce the working strength, improve the working efficiency. The next step should be according to the changing of teaching demand of the corresponding module, on the basis of further optimize system process, reduce the cost.

\section{REFERENCES}

[1] YANG jin-cui, FANG bin-xing, ZGAI li-dong. Reserach towards to toriented universal control system security model. journal on Communications, 2012, 33(11): 49-55. 